Original Research Article

\title{
Assessment of serum sodium levels in patients of lower respiratory tract infections (LRTI) in children at tertiary care center
}

\author{
Jain S. ${ }^{1}$, Kumar V. ${ }^{2}$, Kapoor S. ${ }^{3}$, Bhalke S. ${ }^{4}$, Gupta S. ${ }^{5}$ \\ ${ }^{1}$ Dr. Shruti Jain, JR, Department of Pediatrics, ${ }^{2}$ Dr. Vinod Kumar, Assistant Professor, Department of Pediatrics, ${ }^{3}$ Dr. Sangeeta \\ Kapoor, Professor, Department of Biochemistry, ${ }^{4}$ Dr. Santosh Bhalke, Professor, Department of Pediatrics, ${ }^{5}$ Dr. Shivanshu \\ Gupta, JR, Department of Emergency all authors are affiliated with Teerthanker Mahaveer Medical College, Moradabad, Uttar \\ Pradesh, India.
}

Corresponding Author: Dr. Vinod Kumar, Assistant Professor, TMMC \& RC, NH-24, Delhi Road, Bagadpur, Moradabad, Uttar Pradesh, India. E-mail: vinodmbbs52@gmail.com

\begin{abstract}
Introduction: Lower respiratory tract infection is an infection beneath the larynx which includes: Pneumonia, Wheeze associated Lower respiratory tract infection, Bronchiolitis and Empyema. The aim of this study was to find out the association among hyponatremia and LRTI in tertiary care center. Materials and Methods: The sample size was calculated to be a minimum of 50 subjects. Based on clinical signs and symptoms (as defined by WHO) and infiltrates present on chest X-ray diagnosis of LRTI such as Pneumonia, Bronchiolitis was made. Then patients were subjected to routine investigations such as: Complete blood count, Serum electrolyte (serum sodium) at the time of admission, on day 2 and day 3 by Ion selective electrodes. Results: Mild hyponatremia was found among 11 patients (16.92\%), moderate among 9 (13.85\%) and severe among $2(3.08 \%)$ patients. Hyponatremia was found to be more common among 1 to 5 years age group as compared to $\geq$ 2months to 12 months and $>5$ to 12 years age groups. Conclusion: Hyponatremia is a significantly common association among hospitalized children with lower respiratory tract infections and it is mainly due to syndrome of inappropriate antidiuretic hormone secretion (SIADH).
\end{abstract}

Keywords: Hyponatremia, Pneumonia, Lower respiratory tract infections.

\section{Introduction}

Lower respiratory tract infection is an infection beneath the larynx which includes: Pneumonia, Wheeze associated LRTI and Bronchiolitis, Empyema. Microbial lodgment causing inflammation of airways below larynx is LRTI. [1]. Among young children main cause of lower respiratory tract infection are Pneumonia as well as Bronchiolitis [2]. Annually Pneumonia itself accounts for 1.2 million (18\% total) of all under five years of age death [3] and causing death of 2500 children daily [4]. As per UNICEF in 2016, deaths occurred due to pneumonia was recorded as 90000 [4]. As per World Health Organization (WHO) data, it was estimated that occurrence of clinical pneumonia in youngsters with age less than five years is close to 155.84 million annually in world. Out of them up to $10 \%$ of all new pneumonia cases may grow in to serious episodes and needs hospital admission [5]. As per reports in 2017, Pneumonia accounted for nearly 808694 deaths among children below the age of 5 worldwide [6] of which India accounted for 50 percent i.e. 4 lakh deaths.

Manuscript received: $4^{\text {th }}$ November 2019

Reviewed: $14^{\text {th }}$ November 2019

Author Corrected: $20^{\text {th }}$ November 2019

Accepted for Publication: $23^{\text {rd }}$ November 2019
Pneumonia, severe disease of respiratory tract which is one of the great cause of morbidity and death in young children specifically in the underdeveloped nations. Bronchiolitis, which is another common childhood problem caused by virus i.e. respiratory syncytial virus (RSV). However only $1 \%$ of affected youngster requires hospital admission mainly due to dehydration, improper oral intake, or respiratory distress. "The imminent respiratory failure would require intensive care of about 10-15 percent of hospitalized children." In various acute infections such as Pneumonia, Hyponatremia is a frequent electrolyte imbalance found which complicate the treatment and outcome [7].

Hyponatremia is characterized as a serum sodium value less than $135 \mathrm{meq} / \mathrm{L}$ [8]. Most common type of hyponatremia is mild type and is asymptomatic whereas severe hyponatremia is found rarely and if not treated on time then causes high rates of morbidity and death with poor prognosis [9, 10]. In Lower Respiratory Tract Infection, there are various factors such as foremost ailment, decreased water excretion, inappropriate 


\section{Original Research Article}

vasopressin secretion (SIADH), use of low osmolality fluids, fluid and electrolyte imbalance, and use of numerous drugs may lead to the increase of hyponatremia [11]. Electrolyte imbalances may remain unrecognized many times contributing significantly to the morbidity and mortality, irrespective of the initial problem. This may lead to alarming consequences if abnormalities of serum electrolyte concentration remain undetected and untreated.

Thus, this study was conducted to determine frequency of hyponatremia in children and an attempt has been made to correlate the possible electrolyte disturbances in children suffering from severe pneumonia and their outcome and particularly correlation of hyponatremia with SIADH.

\section{Materials and Methods}

This is an observational, prospective and hospital-based study conducted in "Teerthanker Mahaveer Medical College \& Research Center, Moradabad” from June 2018 to July 2019. The sample size was calculated to be a minimum of 50 subjects.

Inclusion criteria: Children of age $>2$ months to 12 years with a diagnosis of LRTI were involved in this work

\section{Exclusion criteria}

1. Infants $<2$ months of age.

2. Children $>12$ years of age.

3. Children who are on drug therapy which can cause hyponatremia such as diuretics.

4. Children with diagnosed case of tuberculosis and asthma are excluded.

5. Children who are having hyperlipidemia, hyperproteinemia, hyperglycemia are also excluded
6. All children whose parents or guardian refused to give consent.

All patients admitted in to the PICU and pediatric ward were included in the present study. Written and informed consent was secured from the parents participating in the study. The clinical profile of all patients were studied in detail i.e. history and clinical examination. Based on clinical signs and symptoms (as defined by WHO) and infiltrates present on chest X-ray diagnosis of LRTI such as Pneumonia and Bronchiolitis was made.

Then patients were subjected to routine investigations such as: Complete blood count, Serum electrolyte (serum sodium) at the time of admission, on day 2 and day 3 by Ion selective electrodes. Hyponatremia is characterized as mild serum sodium concentration $=131-134$ meq $/ \mathrm{L}$, moderate hyponatremia $=126-130 \mathrm{meq} / \mathrm{L}$ and severe hyponatremia $=$ less than $125 \mathrm{meq} / \mathrm{L}$. Presence of severity of hyponatremia was compared with type of pneumonia and other lower respiratory tract infections based on x-ray findings.

The data were collected regarding duration of hospital stay in PICU or Ward, need of oxygen, need of ventilator support and duration of mechanical ventilator and the final outcome of the patient in terms of complications, discharge and death and will be assessing hyponatremia in terms of morbidity and mortality in pneumonia patients in comparison to patients of pneumonia with normonatremia.

Statistical analysis: The data was entered into the Microsoft excel and the statistical analysis was performed by statistical software SPSS version 21.0. The p-value was considered to be significant when less than 0.05 .

\section{Results}

The sample population consisted of children $\geq 2$ months -12 months $(38,58.5$ percent $), 1-5$ years $(17,26.2 \%)$ and $>5-12$ years (10, 15.4 percent). There were 37 (56.9\%) male children and 28 (43.1\%) female children in the present study population. Mild hyponatremia was found among 11 (16.92\%), moderate among 9 (13.85\%) and severe among 2 (3.08\%) patients. Hyponatremia was found to be more among 1 year- 5 years age group compared to $\geq 2$ months- 12 months and $>5-12$ years age groups. In the current study no significant difference in the allotment of hyponatremia in infancy period, 1-5 years and $>5-12$ years was observed (Table 1).

Table-1: Allotment of sample group according to age group and Hyponatremia

\begin{tabular}{|c|c|c|c|c|c|c|}
\hline & \multicolumn{4}{|c|}{ Hyponatremia } & \multirow[t]{2}{*}{ Total } & \\
\hline Age & Absent & $\%$ & Present & $\%$ & & $\%$ \\
\hline$\geq 2$ months -12 & 26 & $68.4 \%$ & 12 & $31.6 \%$ & 38 & $100.0 \%$ \\
\hline $1-5$ years & 10 & $58.8 \%$ & 7 & $41.2 \%$ & 17 & $100.0 \%$ \\
\hline$>5-12$ years & 7 & $70.0 \%$ & 3 & $30.0 \%$ & 10 & $100.0 \%$ \\
\hline Total & 43 & $66.2 \%$ & 22 & $33.8 \%$ & 65 & $100.0 \%$ \\
\hline
\end{tabular}

Chi-square test $=0.561$, p-value: 0.755 
Original Research Article

Table-2: Comparison of mean Laboratory values between subjects with and without hyponatremia

\begin{tabular}{|c|c|c|c|}
\hline Laboratory values & $\begin{array}{c}\text { Hyponatremia } \\
\text { Mean } \pm \text { SE }\end{array}$ & $\begin{array}{c}\text { Normonatremia } \\
\text { Mean } \pm \text { SE }\end{array}$ & p-value \\
\hline Hemoglobin $(\mathrm{gm} / \mathrm{dl})$ & $9.54 \pm 1.55$ & $10.09 \pm 2.09$ & 0.282 \\
\hline TLC ( cells /cumm) & $17513.23 \pm 8970.94$ & $15744.77 \pm 6198.42$ & $0.035^{*}$ \\
\hline Neutrophils (\%) & $61.68 \pm 17.63$ & $57.07 \pm 20.19$ & 0.367 \\
\hline Lymphocyte (\%) & $30.82 \pm 16.13$ & $35.51 \pm 19.46$ & 0.335 \\
\hline Platelet count (lakh/cumm) & $3.72 \pm 1.67$ & $4.13 \pm 1.44$ & 0.303 \\
\hline ESR $(\mathrm{mm} / \mathrm{hr})$ & $20.41 \pm 7.21$ & $18.91 \pm 8.19$ & 0.470 \\
\hline
\end{tabular}

In the present study mean haemoglobin value found to be lesser among subjects with hyponatremia however the variance was statistically insignificant $(\mathrm{p}=0.282)$. Mean TLC count found to be significantly more among subjects with hyponatremia compared to subjects without hyponatremia $(\mathrm{p}=0.035)$.

Mean Neutrophils count were more among subjects with hyponatremia and mean Lymphocyte count was lesser among subjects with hyponatremia though the difference was statistically insignificant. In the current study mean Platelet count was lesser among subjects with hyponatremia though the difference was not statistically significant. Mean ESR value was more among subjects with hyponatremia though the difference was not statistically significant. (Table 2)

Table-3: Distribution of study population according to cause of Hyponatremia

\begin{tabular}{|c|c|c|}
\hline Cause of Hyponatremia & Number & Percentage \\
\hline Other & 6 & $27.3 \%$ \\
\hline SIADH & 16 & $72.7 \%$ \\
\hline Total & $\mathbf{2 2}$ & $\mathbf{1 0 0 . 0} \%$ \\
\hline
\end{tabular}

SIADH was found among $16(72.2 \%)$ and other causes among $6(27.3 \%)$ patients.

Table-4: Comparison of complications and mortality between subjects with severity of hyponatremia

\begin{tabular}{|c|c|c|c|c|c|c|}
\hline & \multicolumn{4}{|c|}{ Hyponatremia } & \multicolumn{2}{c|}{ Total } \\
\cline { 2 - 7 } & Absent & \% & Present & \% & \multicolumn{1}{c|}{} & $1.50 \%$ \\
\hline Complication & 1 & $2.30 \%$ & 0 & $0.00 \%$ & 3 & $4.60 \%$ \\
\hline Death & 1 & $2.30 \%$ & 2 & $9.10 \%$ & 61 & $93.80 \%$ \\
\hline Discharged & 41 & $95.30 \%$ & 20 & $90.90 \%$ & 65 & $100.00 \%$ \\
\hline Total & 43 & $100.00 \%$ & 22 & $100.00 \%$ & 65 & 1 \\
\hline
\end{tabular}

Chi-square test value $=1.985$, pvalue: 0.371

After using the chi-square test the complications and mortality were compared between subjects with severity of hyponatremia. Complications and mortality was found to be significantly more among subjects with moderate and severe hyponatremia (Table 4).

\section{Discussion}

In this prospective study, the occurrence of hyponatremia and outcome of hyponatremia in terms of morbidity and mortality in lower respiratory tract infection patients has been studied. Hyponatremia is the most common electrolyte abnormality in young children with lower respiratory tract disorders in hospital [12]. Hyponatremia in children with disorders in lower respiratory tract significantly increases the morbidity and death rates [7, $13]$.
The study population contained 37 (56.9 percent) males and 28 (43.1 percent) females in the present study. The similar data was obtained in the study done by Attri et al [14] where there were $70 \%$ male children and $30 \%$ female children and Mhatre et al [15] notes that males with hyponatremia were twice as often affected in acute lower respiratory tract infections as females. The prevalence of hyponatremia in the present study was 33.8\%. Out of $33.8 \%$ hyponatremia cases, mild hyponatremia found to be

Pediatric Review: International Journal of Pediatric Research Available online at: www.medresearch.in 574|P a g e 


\section{Original Research Article}

in $16.92 \%$ cases, moderate among $13.85 \%$ and severe among $3.08 \%$ patients. This was similar to Attri et al's analysis in which hyponatremia was present in 33\% of children who were hospitalized due to lower respiratory tract infections which is comparable to few other studies done in India where the hyponatremia ranges from $27-$ $31 \%[11,12]$.

This was quite similar to the article by Mhatre et al,[15] which revealed that from 36 children who were diagnosed hyponatremia with lower respiratory tract disorders, 25 children $(69.4 \%)$ had mild decrease in sodium levels, eight children $(22.2 \%)$ had moderate hyponatremia and 3 cases $(8.3 \%)$ had severe hyponatremia, whereas in Chaitra $\mathrm{K} \mathrm{M}$ et al, were noted that out of 41 cases of hyponatremia related with lower respiratory tract disorders, twenty nine cases $(70.7 \%)$ had mild decrease in sodium levels, nine (21.9\%) had moderate hyponatremia and $3(7.3 \%)$ had severe hyponatremia [1].

A study done by Channawar K S, states that out of 54 diagnosed hyponatremia cases, 10 cases ( 18.5 percent) had moderate type of hyponatremia and three ( 5.5 percent $)$ had severe hyponatremia [16]. In study done by Sakellaropoulou A et al. out of 54 cases, 18 patients (33.3percent) had mild and one patient (1.9percent) had moderate hyponatremia [7].

Positive CRP was found to be significantly more among subjects with hyponatremia as compared to subjects without hyponatremia. Kanai et al [17] reported that during admission severity of fever and CRP levels both are early features of hyponatremia.

In patients with respiratory tract infections, inflammation itself causes SIADH. New researches revealed that endogenous cytokines such as interleukin-1 $\beta$ and interleukin 6 also play a key role in the formation of inflammatory hyponatremia and might be linked with ADH secretion $[18,19]$.

A number of other studies showed similar observations. A prospective study done by Singhi et al [20] concluded that presence of severe hyponatremia is associated with a threefold increase in the risk of death. Another prospective study done by Dhawan and associates [11] also noticed a 3.5 times higher mortality in patients with hyponatremia when compared to those with normonatremia.

\section{Conclusions}

It can be concluded that, in two months to five years of age group, hyponatremia is a significantly common association among hospitalized children with lower respiratory tract infections and it is chiefly due to inappropriately excessive antidiuretic hormone secretion (SIADH). Children suffering from LRI's should be evaluated not only clinically but also for serum sodium levels at the time of admission.

Careful fluid management especially in the form of fluid restriction therapy in addition to the specific treatment of the underlying cause can prove very useful in lowering the morbidity and complications in these children.

\section{What the study adds to the existing knowledge?}

In two months to five years of age group, hyponatremia is a significantly common association among hospitalized children with lower respiratory tract infections and it is chiefly due to inappropriately excessive antidiuretic hormone secretion (SIADH).

\section{Author's contribution}

Dr. Shruti Jain: Concept, study design, manuscript preparation

Dr. Vinod Kumar: Statistical analysis

Dr. Sangeeta Kapoor: Manuscript preparation

Dr. Santosh Bhalke: Statistical analysis

Dr. Shivanshu Gupta: Manuscript preparation

Funding: No funding sources

Conflict of interest: None declared

Ethical Approval: This study was approved by the Institutional Ethics Committee

\section{Reference}

1. Chaitra KM, Kumar MN, Reddy SG. Hyponatremia in lower respiratory tract infections. Int $\mathrm{J}$ Contemp Pediat. 2016;3(2):381-384. doi: http://dx.doi.org/10.18203/23493291.ijcp20161018.

2. Chang AB, Chang CC, O'Grady K, Torzillo PJ. Lower respiratory tract infections. Pediatr Clin North Am. 2009; 56(6):1303-1321. doi: 10.1016/j.pcl.2009.09.003.

3. Kliegman RM, Stanton BF, ST Geme, Schor NF. Nelson textbook of pediatrics. First South Asia ed. India. Elsevier Health Sci; 2016;2:2088-2094.

4. UNICEF. One is too many: Ending child deaths from pneumonia and diarrhea. New York. UNICEF 2016.

5. Rudan I, Boschi-Pinto C, Biloglav Z, Mulholland K, Campbell H. Epidemiology and etiology of childhood pneumonia. Bullet World Health Organiz. 2008; 86(5): 408-416. 
Original Research Article

6. World Health Organization. Pneumonia Factsheet. Geneva: WHO; 2019 Aug 2.

7.Sakellaropoulou A, Hatzistilianou M, Eboriadou M, Athanasiadou PF. Hyponatremia in cases of children with pneumonia. Arch Med Sci. AMS. 2010; 6(4): 578583.

8. Roberts KE. Pediatric fluid and electrolyte balance: critical care case studies. Crit Care Nurs Clin North Am. 2005; 17(4):361-373. doi: https://doi.org/10.1016/j.ccell. 2005.07.006.

9. Moritz ML, Ayus JC. Disorders of water metabolism in children: hyponatremia and hypernatremia. Pediatr Rev. 2002;23(11):371-380. doi: https://doi.org/10.1542/pir.2311-371.

10. Reynolds RM, Padfield PL, Seckl JR. Disorders of sodium balance. BMJ 2006;332(7543):702-705. doi: https:// doi.org/10.1136/bmj.332.7543.702.

11. Singhi S, Dhawan A. Frequency and significance of electrolyte abnormalities in pneumonia. Indian pediatrics. 1992;29(6):735-740.

12. Dhawan A, Narang A, Singhi S. Hyponatremia and the inappropriate $\mathrm{ADH}$ syndrome in pneumonia. Ann Trop Paediatr. 1992;12(4):455-462.

13. Nair V, Niederman MS, Masani N, Fishbane S. Hyponatremia in community-acquired pneumonia. Am J Nephrol. 2007;27(2):184-190. doi: https://doi.org/10.1159/ 000100866 .
14. Attri HK, Singh T, Vandana, Sehgal G, Kumar K. Impact of Hyponatremia on Clinical Presentation and Management in Pediatric Patients with lower Respiratory Infections. JMSCR. 2019;07(06):21-28. doi: https://dx.doi. org/10. 18535/jmscr/v7i6.05.

15. Mhatre SS, Kumbhar SG. Study of hyponatremia in paediatric patients with acute lower respiratory tract infection. J Evolution Med Dent Sci. 2019;8(21):17041707. doi: 10.14260/jemds/2019/375.

16. Channawar KS, Deshmukh N, Prasad VS. Correlation of hyponatremia in children with lower respiratory tract infection--an institutional observational study. J Evol Med Dental Sci. 2016;5(88):6533-6536. doi: 10.14260/jemds/ 2016/1478.

17. Kanai H, Sato Y, Ichihashi K. Hyponatremia in patients with respiratory syncytial virus bronchiolitis. Pediatr Health, Med Therapeut. 2012;3:39-43. doi: https:// doi.org/10.2147/PHMT.S33121.

18. Swart RM., Hoorn, EJ., Betjes, MG., Zietse, R. Hyponatremia and inflammation: the emerging role of interleukin-6 in osmoregulation. Nephron Physiol. 2011; 118(2):45-51. doi: 10.1159/000322238. Epub 2010 Dec 22

19. Park, SJ., Shin JI. Inflammation and hyponatremia: an under recognized condition? Korean J Pediatr. 2013; 56(12):519-522. doi: 10.3345/kjp.2013.56.12.519.

20. Singhi S, Prasad SVSS, Chugh KS. Hyponatremia in Sick Children: A Marker of Serious Illness. Indian Pediat.r 1994;31(1):19-25

\section{How to cite this article?}

Jain S, Kumar V, Kapoor S, Bhalke S, Gupta S. Assessment of serum sodium levels in patients of lower respiratory tract infections (LRTI) in children at tertiary care center. Int J Pediatr Res.2019; 6(11): 572-576.doi:10.17511/ijpr.2019.i11.04 